\title{
Erratum to: Turning a Lean Business \\ Model into a Successful Start-up \\ in the Wearable Technology Sector: \\ The Case of Clara Swiss Tech
}

Marco Dal Lago, Donatella Corti and Paolo Pedrazzoli

\section{Erratum to:}

Chapter 10 in: R. Rinaldi and R. Bandinelli (eds.), Business Models and ICT Technologies for the Fashion Supply Chain, Lecture Notes in Electrical Engineering 413, 10.1007/978-3-319-48511-9_10

In the original version of the book, incorrect Given name and Family name for author "Marco Dal Lago" in Chapter 10 have to be corrected in chapter Meta data. The erratum chapter and the book have been updated with the change.

The updated online version for this chapter can be found at http://dx.doi.org/10.1007/978-3-319-48511-9_10 